\title{
Occupational Hearing Hazards among Informal Sector Welders in Lubumbashi, Democratic Republic of Congo
}

\author{
Nowa Mutangala1, Mor Ndiaye ${ }^{2}$, André Ngombe Kaseba ${ }^{3}$, Clarence Mukeng ${ }^{4}$, \\ Philippe Mulenga Cilundika ${ }^{4}$, Eric Sompwe Mukomena ${ }^{3,4}$ \\ ${ }^{1}$ Ruashi Mining, Lubumbashi, Democratic Republic of Congo \\ ${ }^{2}$ Occupational Medicine Service, Faculty of Medicine, University Cheikh Anta Diop (UCAD), Dakar, Senegal \\ ${ }^{3}$ School of Public Health, University of Lubumbashi, Lubumbashi, Democratic Republic of Congo \\ ${ }^{4}$ Department of Public Health, School of Medicine, University of Lubumbashi, Lubumbashi, Democratic Republic of Congo \\ Email: andrekaseba86@gmail.com
}

How to cite this paper: Mutangala, N., Ndiaye, M., Kaseba, A.N., Mukeng, C., Cilundika, P.M. and Mukomena, E.S. (2021) Occupational Hearing Hazards among Informal Sector Welders in Lubumbashi, Democratic Republic of Congo. Health, 13, 995-1009. https://doi.org/10.4236/health.2021.139075

Received: July 13, 2021

Accepted: September 14, 2021

Published: September 17, 2021

Copyright $\odot 2021$ by author(s) and Scientific Research Publishing Inc. This work is licensed under the Creative Commons Attribution International License (CC BY 4.0).

http://creativecommons.org/licenses/by/4.0/

\begin{abstract}
Introduction: Noise, an undesirable sound which is found in all areas of occupational activity, is still a matter of concern given the damage it causes. Various machines and tools, from simple to sophisticated ones, produce several types of noise in the workplace. The purpose of this study was to assess the current status of occupational hearing loss among informal sector welders in the city of Lubumbashi, in the Democratic Republic of Congo. Methods: This was a descriptive cross-sectional study which was conducted among 122 informal sector welders over a period of five months. The study used an anonymous questionnaire on noise exposure in the workplace and collected audiometric data of welders. The survey collected data on welders who had a minimal three-year duration of employment without the morbidity associated with the Ear Nose Throat (ENT) region. Socio-professional data (age, duration of employment, sex, education), noise exposure, awareness of hazards and audiometric data were taken into account. Results: 122 questionnaires were completed by male subjects, or $100 \%(n=122)$. The mean age of welders was $36.37 \pm 11.91$ years with extremes being 20 and 63 years. The mean duration of employment was $11.51 \pm 9.6$ years with extremes being 3 and 44 years. Audiometric data have shown $37.96 \%(\mathrm{n}=41)$ of occupational hearing loss. Three degrees of hearing loss were recorded, notably mild hearing loss standing at $80.49 \%(\mathrm{n}=33)$; moderate and severe hearing loss standing at $2.44 \%(\mathrm{n}$ $=1)$. Ninety-six percent $(\mathrm{n}=117)$ of welders reported not using personal protective equipment $(\mathrm{PPE})$ and $1 \%(\mathrm{n}=111)$ were aware of the hazard associated with noise exposure in the workplace. A correlation was found between
\end{abstract}


welders with an advanced age $(\mathrm{p}<0.001 ; \mathrm{RP}=3.66(2.16-6.22))$ and hearing loss, and between the duration of employment and hearing loss $(\mathrm{p}<0.001$; $\mathrm{RP}=6.48$ (3.32 - 12.65)). Conclusion: In the study area, occupational hearing loss among welders is a relevant fact. Three degrees of hearing loss were identified. Most of those suffering from it have developed a mild type of hearing loss whose continued development can be stopped. Despite the fact that welders are aware of the hazards associated with noise exposure in the workplace, they hardly protect themselves. Lack of a culture of prevention and poor enforcement of the existing laws could account for such a situation. There seems to be a crucial need to put in place a program for protecting the welders' auditory organs in the workplace.

\section{Keywords}

Audiometry, Informal Sector Welders, Lubumbashi, DRC

\section{Introduction}

Noise, an undesirable sound which is found in all areas of occupational activity, is still a matter of concern given the damage it causes. Various machines and tools, from simple to sophisticated ones, produce several types of noise in the workplace [1]. The context in this study involves informal sector welders who seem to be downplaying the hazard associated with noise in their work environment and who are regrettably and constantly exposed to high-intensity noise. Such chronic exposure to high intensity noise results in diseases that directly affect the ear and other organs [1] [2]. Occupational hearing loss is any decline or loss of hearing that occurs as a result of being exposed to loud noise in the workplace [2]. Most often, the lesion gradually develops over several decades of exposure. Sensory cells of the inner ear are affected and when damaged, they may cause wear on the auditory nerve fibers that connect the inner ear to higher auditory pathways [3]. Hearing damage is partial and affects the detection of high frequencies. Thereafter, as exposure to noise continues, hearing damage worsens and gradually affects medium and low frequencies. Occupational hearing loss symmetrically affects both ears. In some jobs, notably truck driving; farming or conducting some noisy tasks, when an ear is more exposed to noise, hearing loss can be asymmetrical [4]. In addition to noise, chronic exposure to welding fumes can cause occupational hearing loss [5].

Apart from damaging the ear, exposure to noise in the workplace can cause stress; fatigue; hypertension; isolation, disability. Occupational hearing loss has been the subject of several studies around the world, particularly in France and Canada.

In Canada, two surveys conducted in Quebec in 2007-2008 showed that between 287,000 and 359,000 workers were exposed to intense noise levels, making it difficult for them to talk a few feet or a meter away, even while shouting [5]. 
In France, it accounts for the second most common occupational disease with 600 to 750 new cases recorded each year [6]. Occupational hearing loss continues to be a neglected issue in the Democratic Republic of Congo (DRC). Research in the DRC has not been conducted on occupational hearing loss among welders. In order to address this gap, our study was designed to assess the current status of occupational hearing loss in the welding industry and to collect epidemiological data on its patterns using age, and duration of employment as variables in order to ensure increased awareness of this occupational disease in the city of Lubumbashi. Our study was aimed at describing clinical and epidemiological aspects of occupational hearing loss among informal sector welders who are working in the city of Lubumbashi.

\section{Methods}

\subsection{Study Design and Framework}

The study was a descriptive cross-sectional survey that took place over a period of 5 months, from January 2 to May 31, 2017. It was conducted in the city of Lubumbashi, in the province of Haut-Katanga. Lubumbashi is the second largest city and the economic capital of the DRC. It is located south-east of the country and has an estimated population of 3,000,000 inhabitants. It is subdivided into seven communes, one of which is rural: Annexe commune (rural), Kamalondo, Kampemba, Katuba, Kenya, Lubumbashi and Rwashi [7]. The main activities of the city include Small-scale trade (50\%), Mining (25\%), Urban farming (22\%), Livestock (3\%) [7].

\subsection{Study Population and Selection Criteria}

The study population consisted of informal sector welders in the city of Lubumbashi. The inclusion criterion for eligibility included data on informal sector welders with a minimal three-year duration of employment while exclusion criteria comprised data on informal sector welders with a recent history of flu, quinine intake, a history of a perforated tympanic membrane, drug use, a family history of hearing abnormalities, a history of Meniere's disease, ear tumour, head tumour, meningitis, and mumps. Free class of hearing hazards; 0 at $20 \mathrm{~dB}$ Mild hearing loss, 20 at $40 \mathrm{~dB}$ Moderate hearing loss, 40 at $60 \mathrm{~dB}$ Severe hearing loss.

\subsection{Sampling}

Convenience sampling was adopted as these workers did not have an organized occupational structure.

\subsection{Data Collection Techniques and Tools}

A practical technique involving an otoscopic examination with a wall-mounted WelchyAllyn otoscope was conducted by trained and certified staff. The type 4 smart phone audiometer with TDH39 headphones calibrated in November 2016 
for one year, from 500 to $8000 \mathrm{~Hz}$ was used for the functional examination of hearing. The anonymous pretested questionnaire used to collect socio-demographic data; professional data, noise exposure, working environment and prevention (Annex 1); audiogram measurement (Annex 2); was explained and designed in French and in the local language (Swahili) and this was done after securing prior verbal consent of the welding workshop managers and welders who were found on site. The questionnaire which was modelled after the one used in a similar study in the agricultural industry [8] comprised the following items: professional data on the informal sector welders (age, duration of employment, vocational training, use of PPE, health check); noise exposure and duration.

\subsection{Statistical Analysis of Data}

Data collected were entered processed and analysed using the Stastical Package for Social Sciences (SPSS version 22). Quantitative variables were summarized as means, standard deviations, minimums and maximums, while qualitative variables were presented as numbers, percentages and/or diagrams. The Chi-square test was used to correlate two qualitative variables while the Kappa index was used to assess the asymmetry of hearing loss between the right and left ear. The strength of association between two bivariate data was calculated using the Odds ratio (OR) and $95 \%$ confidence interval (CI). The significance level was set at $5 \%$.

\section{Results}

\subsection{Professional Data}

122 out of 132 questionnaires distributed were returned, which translated to a loss of 7.54\%. A hundred percent of the surveyed population were men $(\mathrm{n}=$ 122), with the mean age being $36.37 \pm 11.91$ years, the oldest welder being 63 years old, the youngest 20 years old (data shown in Figure 1).

Duration of employment stood at $11 \pm 9.6$ years with extremes being 3 and 44 years. Thus, 95 welders out of 122 , or $77.87 \%$ identified noise as causing annoyance as shown in Table 1.

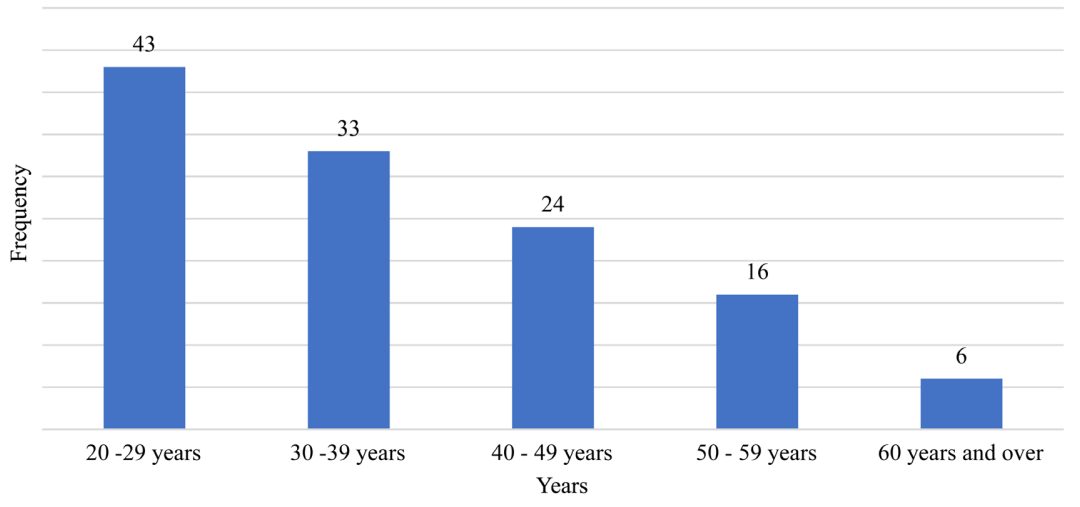

Figure 1. Age group by noise exposure. 
Table 1. Number and percentages of responses on noise as causing annoyance.

\begin{tabular}{ccc}
\hline & Number & Percentage \\
\hline Yes & 95 & 77.87 \\
No & 27 & 22.13 \\
Total & 122 & 100 \\
\hline
\end{tabular}

As regards the most annoying noises, respondents identified those that were related to both metal cutting with disc machine and sheet metal hammering, $33.61 \%(n=41)$. And for functional auditory signs, $33.61 \%(n=41)$ of the affected welders had tinnitus. These data are shown in Table 2 and Table 3.

The duration of noise exposure was a few minutes according to $51.64 \%$ ( $\mathrm{n}=$ 63), 15 minutes for $11.48 \%(\mathrm{n}=14)$; more than one hour according to $9.02 \%$ ( $=12)$, all day according to $5.74 \%(\mathrm{n}=7)$ and no reported duration for $22.13 \%(\mathrm{n}$ =27) of welders. These data are shown in Table 4.

As regards hazards associated with high-intensity noises, almost all welders, that is $91 \%(\mathrm{n}=111)$ reported being aware of hazards associated with loud noises as shown in Figure 2.

The variable on the use of PPE shows that $96 \%(n=117)$ of welders reported not protecting themselves from noises as against $4 \%(n=5)$ who reported being protected as shown in Figure 3.

As for reasons cited for not using personal protective equipment (PPE), 40.16\% of welders mentioned unaffordably high prices (Figure 4).

\subsection{Prevalence of Audiometric Parameters}

Based on an audiometric baseline (benchmarking audiometry), 20 welders (16.39\%) underwent a tone audiometric test as against 102 (83.61\%) (Figure 5).

\section{Audiometric Test Results}

Of 122 welders who completed the questionnaire, only 108 were tested, that is $11 \%$ of the exclusion rate simply because of uncompleted the questionnaire. Prevalence of occupational hearing loss in the study population was $37.96 \%$, or 41 out of 108 tested respondents (95\% CI (37.75\% - 38.17\%), as shown in Table 5.

Mild hearing loss accounted for $80 \%$ of the tested respondents, that is 33 welders out of 41 (Table 6).

\subsection{Measures of Association}

\subsubsection{Association between Hearing Loss and Age, Hearing Loss and Duration of Employment}

Welders aged 40 years or above were four times more likely to have experienced occupational hearing loss $(\mathrm{p}<0.001 ; \mathrm{OR}=3.66(2.16$ - 6.22) (Table 7).

Welders with a duration of employment of more than 10 years were six times more likely to have developed occupational hearing loss $(\mathrm{p}<0.001$; OR $=6.48$ [3.32 - 12.65]) (Table 8). 


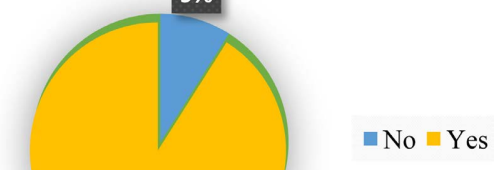

$91 \%$

Figure 2. Awareness about harzards associated with noise.

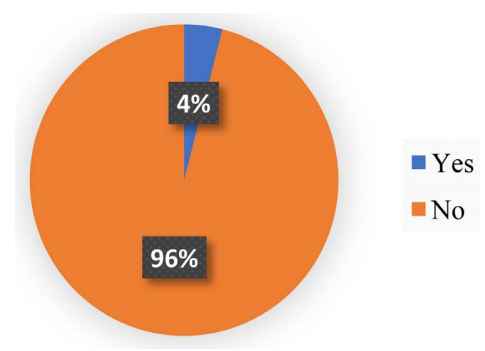

Figure 3. Percentage of responses on protection from noises.

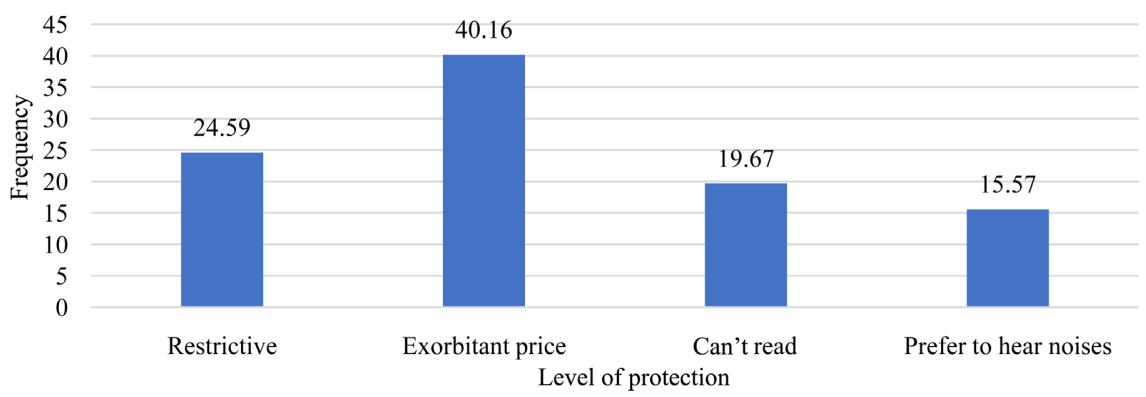

Figure 4. Distribution of responses in percentage on welders not using PPE.

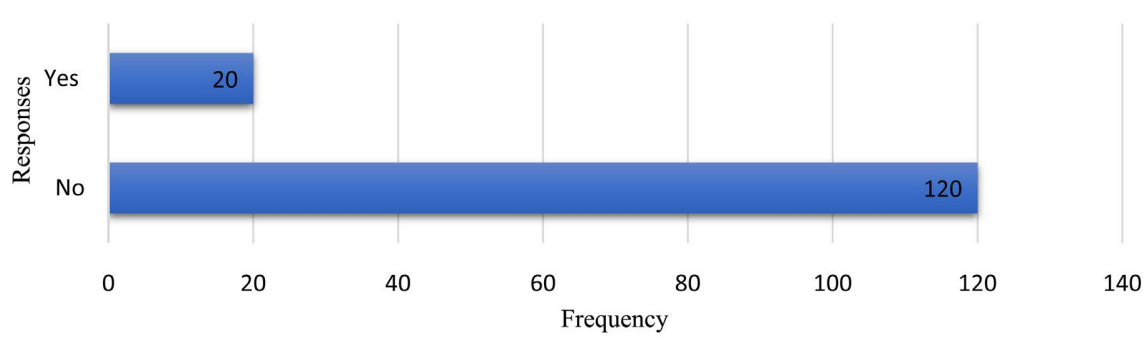

Figure 5. Frequencies of responses on the baseline audiometric test.

Table 2. Number and percentage of responses on the type of noise.

\begin{tabular}{ccc}
\hline & Number (n) & Percentage (\%) \\
\hline Noise from cutting and hammering & 41 & 33.61 \\
Noise from cutting & 33 & 27.05 \\
Noise from hammering & 17 & 13.93 \\
Noise from welding & 6 & 4.92 \\
Nothing & 25 & 20.49 \\
Total & 122 & 100 \\
\hline
\end{tabular}


Table 3. Number and percentages of functional auditory signs.

\begin{tabular}{ccc}
\hline Functional signs & Number $(\mathrm{n})$ & Percentage (\%) \\
\hline Tinnitus & 41 & 33.61 \\
Hearing decline & 18 & 14.75 \\
Dizziness & 17 & 13.93 \\
Auditory fatigue & 12 & 9.84 \\
Ear ache & 7 & 5.74 \\
Nothing & 27 & 22.13 \\
Total & 122 & 100 \\
\hline
\end{tabular}

Table 4. Number and percentage of responses on the duration of noise exposure.

\begin{tabular}{ccc}
\hline & Number & Percentage \\
\hline A few minutes & 63 & 51.64 \\
15 minutes & 14 & 11.48 \\
More than one hour & 11 & 9.02 \\
All day & 7 & 5.74 \\
No duration & 27 & 22.13 \\
Total & 122 & 100 \\
\hline
\end{tabular}

Table 5. Hearing status among tested welders.

\begin{tabular}{ccc}
\hline & Frequency & Percentage \\
\hline Normal hearing & 67 & 62 \\
Mild hearing loss & 33 & 30.6 \\
Moderate hearing loss & 7 & 6.5 \\
Severe hearing loss & 1 & 0.9 \\
Total & 108 & 100 \\
\hline
\end{tabular}

Table 6. Frequency and percentage of various degrees of hearing loss.

\begin{tabular}{ccc}
\hline & Frequency & Percentage \\
\hline Mild hearing loss & 33 & 80.49 \\
Moderate hearing loss & 7 & 17.07 \\
Severe hearing loss & 1 & 2.44 \\
Total & 41 & 100 \\
\hline
\end{tabular}

Table 7. Occupational hearing loss by age.

\begin{tabular}{|c|c|c|c|}
\hline \multirow{2}{*}{ Age } & \multicolumn{2}{|c|}{ Hearing loss } & \multirow{2}{*}{ Total } \\
\hline & Yes & No & \\
\hline$\geq 40$ years & 31 & 9 & 40 \\
\hline$<40$ years & 10 & 55 & 68 \\
\hline Total & 41 & 64 & 108 \\
\hline
\end{tabular}


Table 8. Hearing loss and duration of employment.

\begin{tabular}{cccc}
\hline \multirow{2}{*}{ Duration of employment } & \multicolumn{2}{c}{ Hearing loss } & Total \\
\cline { 2 - 3 } & Yes & No & \\
\hline 10 years & 33 & 9 & 42 \\
$<10$ years & 8 & 58 & 66 \\
Total & 41 & 67 & 108 \\
\hline
\end{tabular}

\subsubsection{Association between Awareness of Hazard and Hearing Loss}

Awareness of noise-related hazards did not find any association with the development of occupational hearing loss $(\mathrm{p}=0.1429$; $\mathrm{OR}=1.53[0.81-2.90])$ (Table 9).

\subsubsection{Measure of Agreement among Observers about the Effect of Noise by Ear}

Asymmetry between the right and left ear showed a significant relationship with hearing loss (Kappa $=0.74 ; \mathrm{p}<0.001)($ Table 10).

The degree of hearing loss by ear showed that both ears were affected by an high-frequency mild hearing loss (Figure 6).

\subsubsection{Indicator of Early Warning Signs and Association between Formal Training and Hearing Loss}

The feedback button indicates that $35 \%(\mathrm{n}=38)$ of welders showed early signs of hearing loss of more than $25 \mathrm{~dB}$ (A), while non-formal training was linked to the development of hearing loss $(\mathrm{p}=0.0138$; OR $=1.7463$ [1.0581 - 2.8822]) (Table 11 and Table 12).

\section{Discussion and Comments}

In total, 122 questionnaires, or $92.46 \%$ out of $132(7.54 \%)$ were answered by respondents, which seems to be a good response rate achieved as a result of close monitoring through regular in-person contact with welding shops managers and welders who had a phone.

As a matter of fact, socio-demographic data show that values on sex which are reported at $100 \%(\mathrm{n}=122)$ in our study are very much like those of a study conducted in Canada (1.3\% of females as against $98.7 \%$ of men) [9], which further corroborates the fact that welding is virtually a male-dominated trade. It might be assumed that African society assigns specific occupations to men and women. The mean age was $36 \pm 12$ years and the age group ranging between 20 and 29 years $(\mathrm{n}=43 ; 36.06 \%)$ was the most represented group in the current study. This is a clear indication that an increasingly great number of youths are being attracted by this job but this finding differs from a study by Kumar, where the majority fell in the age group between 20 and 40 years [10]. Duration of employment of more than 10 years was six times more likely to have a relationship with the risk of developing hearing loss ( $\mathrm{p}<0.001$; OR $=6.48$ IC: $[3.32-12.65])$. Our findings are virtually similar to those of Viyaj et al. [8] $\mathrm{p}<0.001$; OR $=$ 


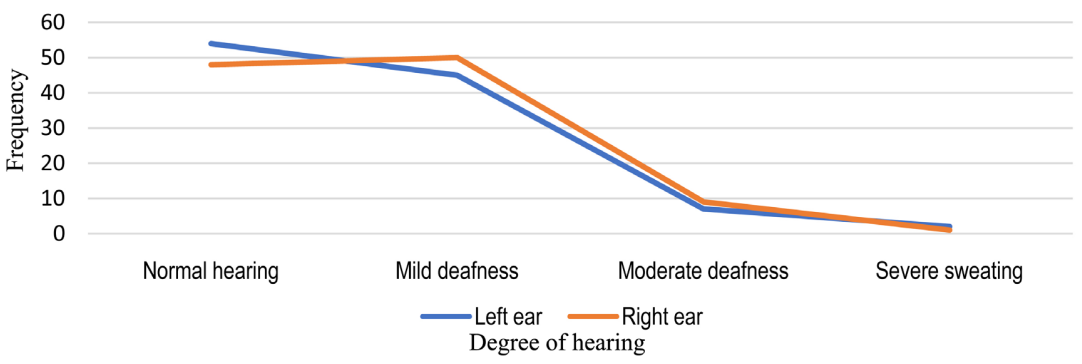

Figure 6. Curves showing degrees of hearing loss by ear.

Table 9. Hearing loss and awareness of noise-related hazards.

\begin{tabular}{|c|c|c|c|}
\hline \multirow{2}{*}{ Awareness } & \multicolumn{2}{|c|}{ Hearing loss } & \multirow{2}{*}{ Total } \\
\hline & Yes & No & \\
\hline No & 5 & 4 & 9 \\
\hline Yes & 36 & 63 & 99 \\
\hline Total & 41 & 67 & 108 \\
\hline
\end{tabular}

Table 10. Hearing loss by ear.

\begin{tabular}{cccc}
\hline & \multicolumn{2}{c}{ Right ear } & Total \\
\cline { 2 - 3 } Left ear & Yes & No & 40 \\
\hline Yes & 33 & 7 & 68 \\
No & 8 & 60 & 108 \\
Total & 41 & 67 & 108 \\
\hline
\end{tabular}

Table 11. Frequencies and percentage of losses.

\begin{tabular}{cc}
\hline Indicators & $\mathrm{n}(\%)$ \\
\hline Loss $<25 \mathrm{~dB}(\mathrm{~A})$ & $70(64.81)$ \\
Loss $>25 \mathrm{~dB}(\mathrm{~A})$ & $38(35.19)$ \\
Total & $108(100)$ \\
\hline
\end{tabular}

Table 12. Association between hearing loss and formal training.

\begin{tabular}{cccc}
\hline \multirow{2}{*}{ Training } & \multicolumn{2}{c}{ HEARINING LOSS } & Total \\
\cline { 2 - 4 } & Yes & No & 51 \\
Non-formal & 25 & 26 & 57 \\
Formal & 16 & 41 & 108 \\
Total & 41 & 67 & \\
\hline
\end{tabular}

18.18; and Sriopas et al. [11], who found that more than 10 years of the duration of employment increased the prevalence of occupational hearing loss [11]. Acquiring welding skills while working on the job was linked to a high risk of developing hearing loss ( $\mathrm{p}=0.0138$; OR $=1.7463$; $\mathrm{CI}$ : [1.0581 -2.8822$]$ ), which was 
evidence of a likely lack of information on safety against noise; our findings are consistent with those of Yu et al. [12]. For Kumar [13], the level of education had a significant association with the use of occupational safety measures [14].

As regards awareness about hazards associated with noise, a section of respondents, that is $91 \%(n=111)$ of welders reported being aware of hazards linked to noise. This finding, unfortunately, is in stark contrast with the low utilization rate of PPE and might not be associated with hearing loss ( $\mathrm{p}=0.1429$; $\mathrm{OR}=1.53$; CI $[0.81-2.90])$ and ninety-six percent $(\mathrm{n}=117)$ of respondents reported being able to protect themselves from noise. Thus, the fact that $86.07 \%$ (n $=105$ ) of welders were not using PPE while having knowledge of the hazard associated with noise and how they could protect themselves from it is an indication that there was no culture of prevention. Our findings concur with those of Viyaj et al. [15] who found that none of the welders used an appropriate type of PPE while inconsistent results were reported by Budhathoki and Kumar [10] [14] [16] who found that $47.7 \%$ and $95.7 \%$ of welders were wearing PPE [8] [13]. It was noted that there was a non-significant difference between neurosensorial hearing loss and welders who were not wearing PPE ( $\mathrm{p}=0.3095$; OR $=1.48$; CI [0.48 - 3.44]). Through such findings, specific characteristics of individuals with regard to acoustic trauma would be demonstrated and would also justify the benefit of protecting the ears against noise. Furthermore, 40.7\% $(n=57)$ of welders had cited unaffordably high prices as the reason for not using PPE, which raises the issue of impoverishment among workers of this industry and how profitable such an occupation can be in our area.

As regards, prevalence and degree of hearing loss, values of $37.96 \%$ of hearing loss among informal sector welders are very much like those of Normand (28\%) [12]; but are by far higher than those of Pawlaczyk-Luszczynska [14] (13.4\%) and those of Yu SF et al. [12] (6.23\%). The high rate of occupational hearing loss in the current study shows the extent to which welders suffer from a lack of job security. Furthermore, degrees of hearing loss that were commonly cited in this study were, in a descending order, mild hearing loss $(\mathrm{n}=33 ; 80.49 \%)$, moderate hearing loss $(\mathrm{n}=7 ; 17.07 \%)$, severe hearing loss $(\mathrm{n}=1 ; 2.44 \%)$. However, our findings which are similar to those of Lavieille [15] (45.4\%; 5.6\% and 0.4\%), highlight the existence of mild hearing loss as a frequent type of hearing loss in occupational activities.

\section{Study Limitation}

Firstly, there was no database and secondly no causal relationship was discovered with respect to noise exposure as our findings were mainly based on verbal reports from welders.

\section{Conclusion}

Welders in Lubumbashi are quite aware of hazards which they face in their working environment but they do not protect themselves. The risk appears to be 
the highest with the duration of employment and a great many welders have been found to suffer from occupational hearing loss. The most frequently cited degree of occupational hearing loss was mild hearing loss. Thus, conducting increased awareness-raising through the welders' union would possibly help ensure prevention and protect the auditory organs of informal sector welders and would eventually help in stopping the continued development of hearing loss among them.

\section{Acknowledgements}

The authors express their gratitude to the entire editing team that participated in this study and supported its publication. Special thanks are due to Professor Ndiaye M and Professor Eric Mukomena Sompwe for their mentorship.

\section{Contributors}

Study design and tools: NM, ANK, NM, implementation and supervision: EMS, analysis and interpretation of data: PMC, ANK, CM, NM, manuscript: all contributors read the manuscript.

\section{Ethics Approval and Informed Consent}

Ethics approval was granted by the University of Lubumbashi and the Ethics committee from the school of medicine at the University of Lubumbashi, DRC (PO box 1825). Occupational medicine service, UCAD Faculty of Medicine Dakar, Senegal and all contributors provided their informed consent prior to engaging in this study.

\section{Conflicts of Interest}

The authors declare no conflicts of interest regarding the publication of this paper.

\section{References}

[1] http://www.ihsa.ca/rtf/manuel_de_sante/Outils/Chapitre41.pdf

[2] Casanova, P. (2014) Cours Magistral: Fonction Auditive. Université Cheik AntaDiop faculté de médecine pharmacie et odontologie, Dakar.

[3] Claude, A. (2012) Dictionnaire Encyclopedic in One Volume. Petit Larousse illustré.

[4] Legent, F., Bordure, P., Calais, C., et al. (2011) Audiologie Pratique Audiométrie. Elsevier Masson, Italie. https://doi.org/10.1016/B978-2-294-70835-0.00003-X

[5] https://inspq.qc.ca/pdf/Publications/1770_Portrait_Surdite_Professionnelle

[6] (2017). http://www.travailetsante.net

[7] Omasombo, J.T. (2018) Haut-Katanga. Musée royal de l'Afrique centrale, Tervuren.

[8] Kumar, S.G., Dharamipriya, A. and Kar, S.S. (2013) Awareness of Occupational Injuries and Utilization of Safety Measures among Welders in Coastal South India. Journal of Occupational and Environmental Medicine, 4, 172-177.

[9] Viyaj, A., Kulandarpalayam, N.C.S., Pradeep, Z., et al. (2016) Occupational Safety 
Measures and Morbidity among Welders in Vellore, Southern India. International Journal of Occupational and Environmental Health, 22, 300-306. https://doi.org/10.1080/10773525.2016.1228287

[10] Sriopas, A., Chapman, R.S., Sutammasa, S. and Siriwong, W. (2017) Occupational Noise-Induced Hearing Loss in Auto Part Factory Workers in Welding Units in Thailand. Journal of Occupational Health, 59, 55-62. https://doi.org/10.1539/joh.15-0291-OA

[11] Yu, S.F., et al. (2017) A Cohort Study on Occupational Noise Induced Hearing Loss Workers at an Iron Steel Plant. Journal of Occupational Health, 51, 13-19.

[12] Normand, J.C., Duclos, J.C., Massardier-Pilonchery, A. and Thiéry, L. (2011) Evaluation du risque lié au bruit par analyse collective d'audiogrammes. Institut universitaire de médecine du travail-UMRESTTE. Université Claude Bernard Lyon1. https://doi.org/10.1016/S1155-1925(10)71874-7

[13] Budhathoki, S.S., Singh, S.B., Sagtari, R.A., Niraula, S.R. and Pokharel, R.K. (2004) Awareness of Occupational Hazards and Use of Safety Measures among Welders: A Cross-Sectional Study from Eastern Nepal. British Medical Journal, 45, 82.

[14] Pawlaczzyk-Luszczyńska, M., Zamojska-Daniszewska, M., Dudarewicz, A. and Zaborowski, K. (2017) Exposure to Excessive Sounds and Hearing Status in Academic Classical Music Students. International Journal of Occupational Medicine and Environmental Health, 30, 55-75. https://doi.org/10.13075/ijomeh.1896.00709

[15] Lavieille, J.P., et al. (2007) Prévalence des surdités en milieu professionnel. Services de médecine du travail. CHU Marseille Nord.

[16] (2017).

https://www.ccq.org/ /media/PDF/Recherche/DossiersSpeciaux/presence_femmes 


\section{Annex 1: Questionnaire on Noise Exposure}

Would you mind completing this questionnaire?

What is your birth date? [//]

Sex

[M]

[F]

How long have you been in this job? [] year(s)

Are you annoyed by noise?

[Yes]

[No]

If yes, what kind of noise annoys you the most?

Noise from welding []

Noise from metal cutting []

Noise from metal hammering []

Noise from cutting and hammering []

At the end of your working day, have you ever experienced

Hearing decline? []

Auditory fatigue? []

Tinnitus (ringing or booming sensation in ears)? []

Dizziness? []

Ear aches? []

In your opinion, how long do you experience such auditory fatigue, hearing decline, tinnitus or ear ache?

A few miniutes? []

Fifteen minutes? []

More than one hour? []

More than 4 hours? []

All day? []

Until the next morning? []

More than one week? []

In your opinion, do you experience these acoustic problems until the next morning?

Never []

Sometimes []

Always []

At work, do you ask your conversation partners to repeat what they say?

At work, where does noise come from?

In your opinion how long do you experience noise exposure?

A few minutes []

Less than one hour []

More than one hour []

More than four hours []

All day [] 
Until the next morning []

More than one week []

Does welding noise produce irreversible hearing loss?

[Yes]

[No]

Can you protect yourself from noise at work?

[Yes]

[No]

Do you protect your ears Protégez-vous les oreilles du bruit en cas de besoin?

[Yes]

[No]

If no, why?

It is demanding []

I do not know to do it []

It is very expensive []

I prefer to hear the noise from machines []

Are you a choir member?

Yes []

No []

Where did you get your training from?

Technical school []

Learning through apprenticeship []

When you are home, do you sometimes work on your own using:

A chainsaw [Yes] [No]

A vibrator [Yes] [No]

A grinder [Yes] [No]

Do you listen to music with headphones for a longer period?

[Yes]

[No]

Have you ever heard of ear protection from noise?

[Yes]

[No]

Have you ever taken an audiometric test?

\section{Annex 2: Wall Mounted Welchy Allyn Otoscope}

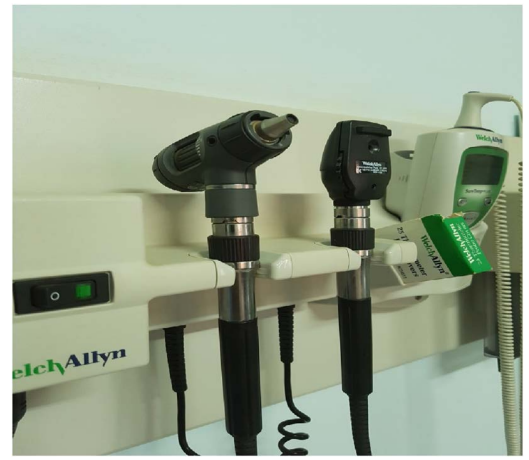




\section{Annex 3: Audiometric Booth}

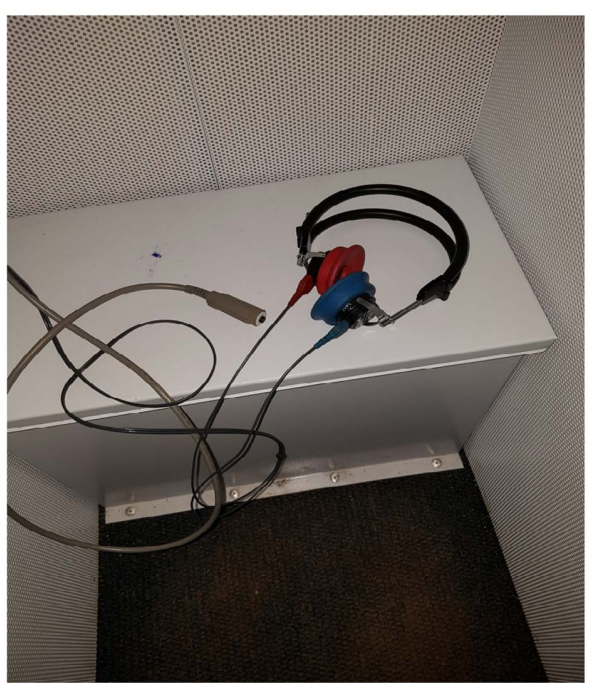

